Tissue Antigens (1981) 18, 24-34

\title{
Antinuclear factors in murine alloantisera
}

\author{
D. A. Saunders*, J. R. Crowder* and J. S. Schultz** \\ *Department of Zoology, Howard University, Washington, DC, ${ }^{* *}$ Department of Human Genetics, \\ University of Michigan School of Medicine, Ann Arbor, Michigan, ${ }^{* *}$ Veterans Administration Medical \\ Center, Ann Arbor, Michigan, USA
}

\begin{abstract}
We have demonstrated that anti-Thy 1.1 and certain $\mathrm{H}-2$ alloantisera contain an antinuclear factor (ANF) detected by fluorescent antimouse IgG. The incidence of ANF positive antisera that we report may actually be an underestimate. ANF is present in sera not only from our laboratory but also from other sources; thus ANF is not an artifact of our laboratory.

ANF is not identical to alloantibody, and the ANF appears to be of an autoimmune nature. A variety of environmental and genetic factors may influence the appearance of ANF in anti-H-2 sera, but we believe that the consistent detection of ANF in sera directed against $\mathrm{H}-2.31,34$ or against $\mathrm{H}-2.4$ suggests that some specific aspect of immune stimulation by these $\mathrm{H}-2$ antigens, and likely by other $\mathrm{H}-2$ antigenic specifications, induces the appearance of ANF. It is not known whether it is these $K$ and $D$ antigens or other determinants associated with the $\mathrm{H}-2$ complex that may actually provide the immune stimulation for ANF induction. The particular mechanisms that may be operating to induce ANF cannot be determined at present. We are continuing with experiments to define what parameters influence the appearance of ANF in alloantisera.
\end{abstract}

Received for publication 15 December 1980, revised, accepted 18 February 1981

Alloantisera directed against antigens coded by the $\mathrm{H}-2$ gene complex have been the primary serological reagent employed by $\mathrm{H}-2$ immunogeneticists. It has been a common working assumption that any anti-H-2 serum reacts specifically with allotypic $\mathrm{H}-2$ gene products if that antiserum is raised in recipient individuals that are $\mathrm{H}-2$ congenic with those providing the donor cells for the immunization; however, during the past several years numerous laboratories have raised questions regarding the specificity of these antisera for products of the donor type $\mathrm{H}-2$ gene complex. For example, it has been demonstrated that many $\mathrm{H}-2$ alloantisera, as well as alloantisera against Thy or Ly antigens, contain antibodies directed against envelope antigens of murine leukemia virus (P. Klein 1975, Nowinski \& Klein 1975, Langdon et al. 1980); such antiviral antibodies are often present in nonimmune mouse sera, but the titre of such antiviral antibodies may increase during alloimmunization (Langdon et al. 1980). Also, H-2 alloantisera need not be specific for the $\mathrm{H}-2$ gene products of only the donor type; Iványi et al. (1979) have demonstrated that $\mathbf{H}-2$ alloantisera can contain antibodies against $\mathrm{H}-2$ specificities that are present in neither the donor nor recipient strains; these authors have suggested that reactions against third 


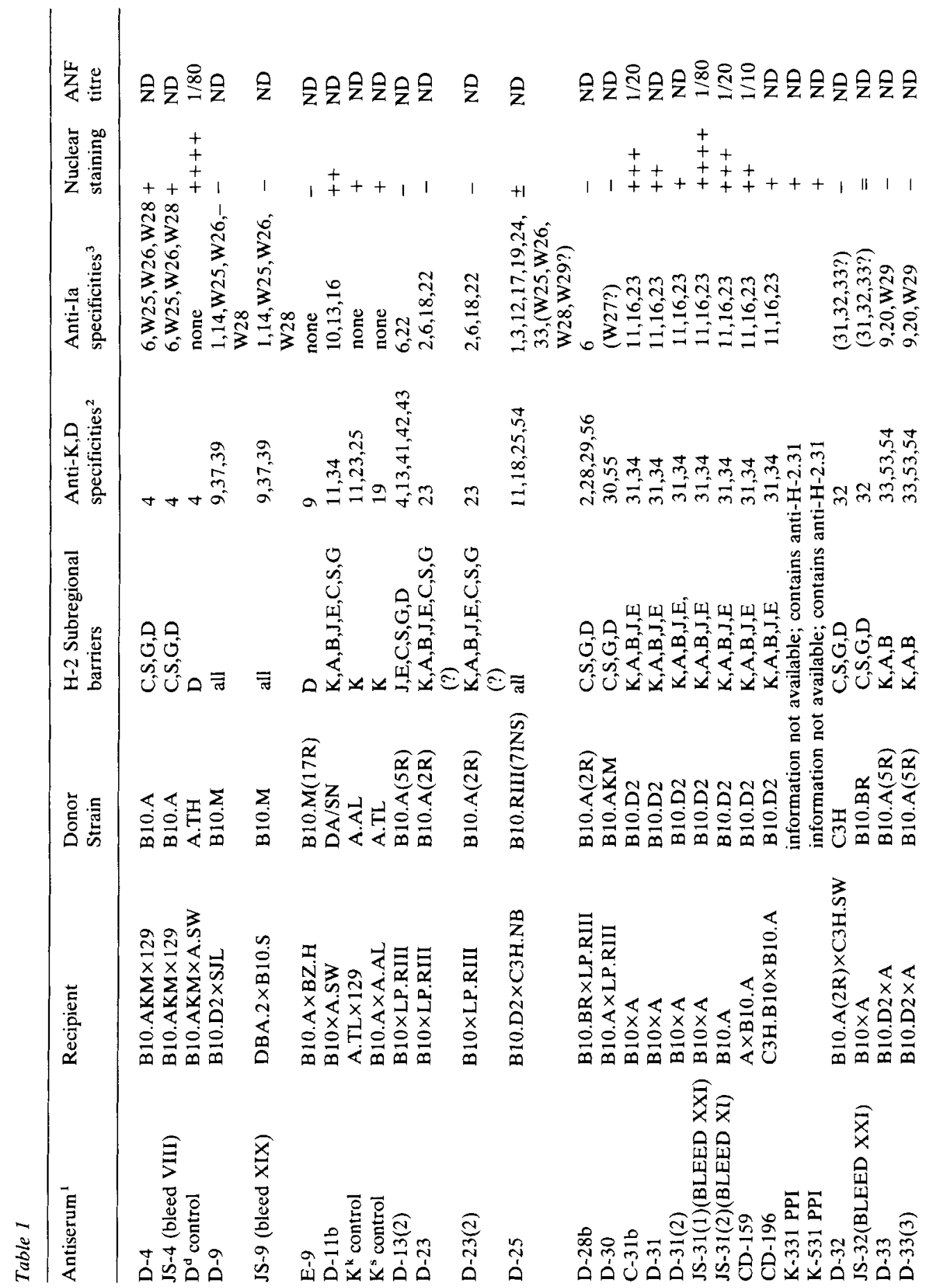




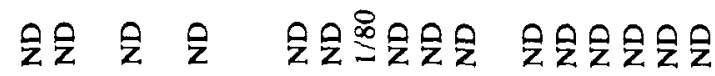

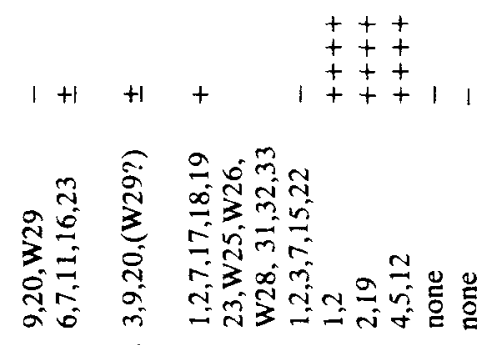

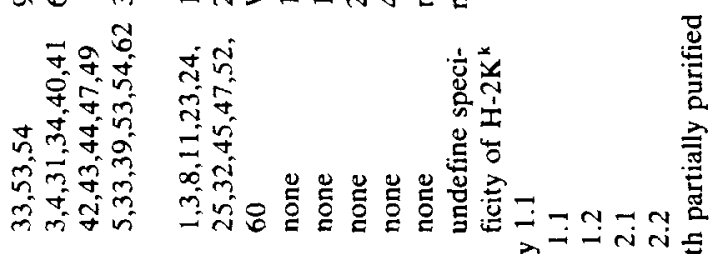

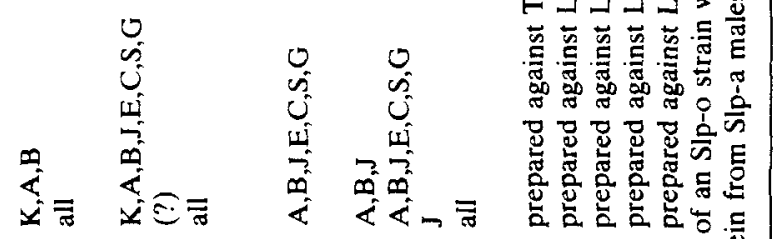

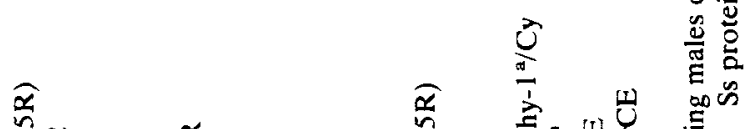

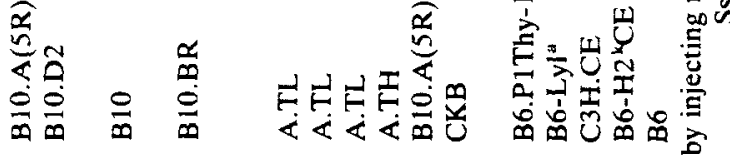

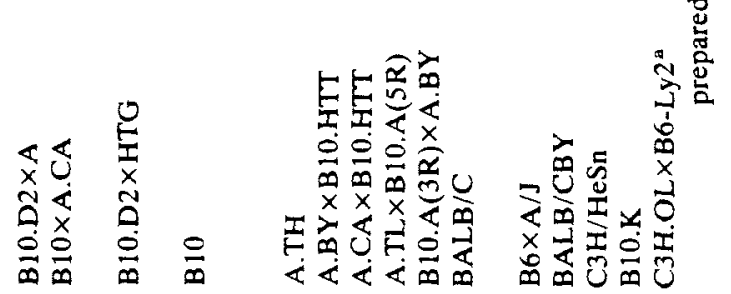

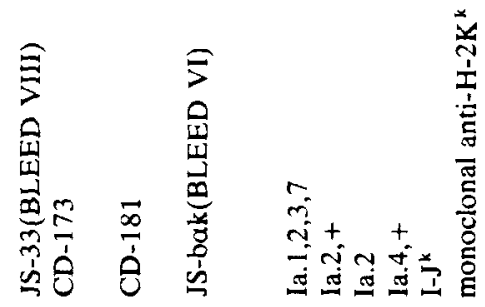

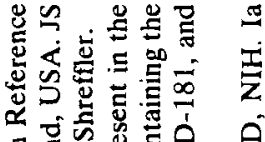

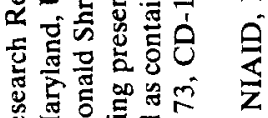

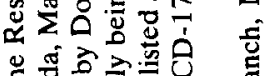

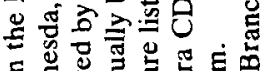

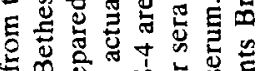

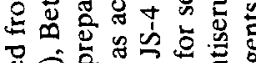

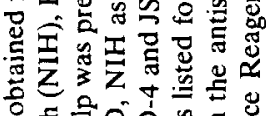

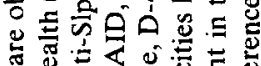

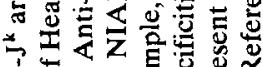

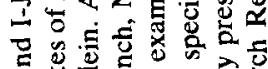

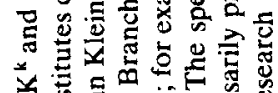

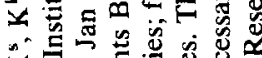

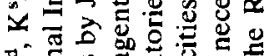

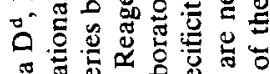

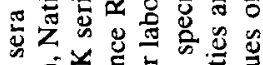

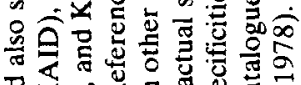

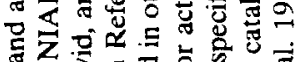

क्षे

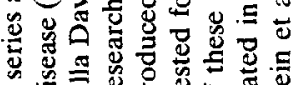

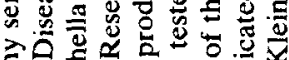

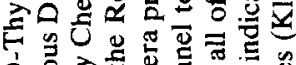

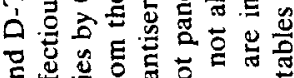

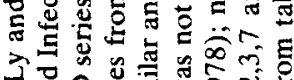

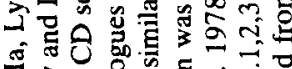

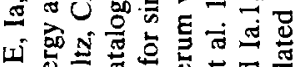

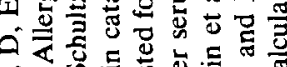
ن 해을

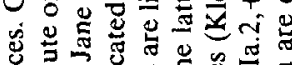

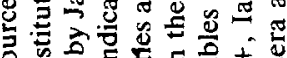

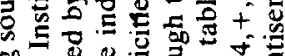

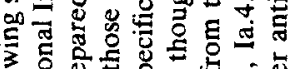

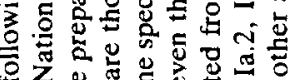
z z

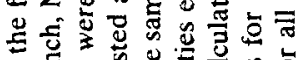
E gin

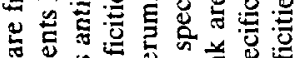
等

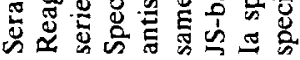


party $\mathrm{H}-2$ antigens might be triggered by virus - induced alterations in $\mathrm{H}-2$ antigens of donor type.

In a previous publication (Saunders et al. 1979) we noted that when some anti-H-2 sera, that had been raised by congenic immunizations, were employed to stain tissue sections by indirect immunofluorescence there was a non- $\mathrm{H}-2$ related staining of cell nuclei. In this present study we have surveyed for antinuclear reactivity among several antisera directed against Thy, Ly, or various $\mathrm{H}-2$ antigenic specificities; and we present evidence that anti-Thy and many of the anti-H-2 sera contain antinuclear factors demonstrable by indirect immunofluorescence, with antimouse IgG as the second layer reagent. This antinuclear reactivity is not specific for Thy or H-2 gene products and is apparently of an autoimmune nature.

\section{Material and methods}

Mice: The animals employed for the immunizations that we conducted are from the sources given by Saunders et al. (1979). For most of the results reported in Table 1 , the substrate liver tissues were from mice obtained either from Dr. M. Edidin, who maintains a colony at Johns Hopkins University, or from Dr. C. Laing, who obtained these from Jackson Laboratories, Bar Harbor, Maine.

Antisera: Table 1 lists all antisera including their sources and the donor-recipient combinations used for immunization. For the $\mathrm{H}-2$ antisera the subregional barriers eliciting the immunization and expected anti-K, Ia, or D specificities are listed. Antisera from our laboratory were prepared as described by Saunders et al. (1979) and were tested for the specificity of their cytotoxic reactions against lymphocytes bearing either all or none of the $\mathrm{H}-2$ specificities putatively contained in the antiserum.

Cytotoxic titres of antisera: These were obtained as described by Saunders et al. (1979).

Conjugate: Fluorescein conjugated IgG fractions from rabbit antimouse $\operatorname{IgG}$ (heavy and light chains) from lots 8864 and 13039 was purchased from Cappel Laboratories, Cochranville, Pennsylvania.

Tissue preparations: Mice were sacrificed by cervical dislocation. The liver was immediately removed and cut into small pieces (approximately $4 \mathrm{~mm}^{3}$ ) and frozen in isopentane at $-70^{\circ} \mathrm{C}$. These tissues were stored at $-80^{\circ} \mathrm{C}$ for up to one month prior to use. Tissues were embedded in O.C.T. compound. (Lab-Tek Products, Naperville, Illinois), cut in sections ten $\mu \mathrm{M}$ thick, and air dried onto slides. In some cases the air dried sections were fixed in acetone at room temperature for ten minutes.

Section staining and scoring: Staining with alloantisera followed the protocol of Gervais (1968). For most experiments the first layer sera were employed at a dilution of $1 / 4$. These were incubated with liver sections that were not expected to react with any of the putative anti-H-2K and D specificities contained in the antiserum. After the final wash the preparations were mounted in Gelvatol 20-30 and stored at $4^{\circ} \mathrm{C}$ in the dark.

Sections were scored for nuclear staining as follows: ( - , no nuclear stain; $( \pm)$, questionable; $(+)$, weak but definite; $(++)$, good; $(+++)$, strong; $(+++)$, very intense. Sections were scored by two observers, and the agreement in scoring was within one gradation. 


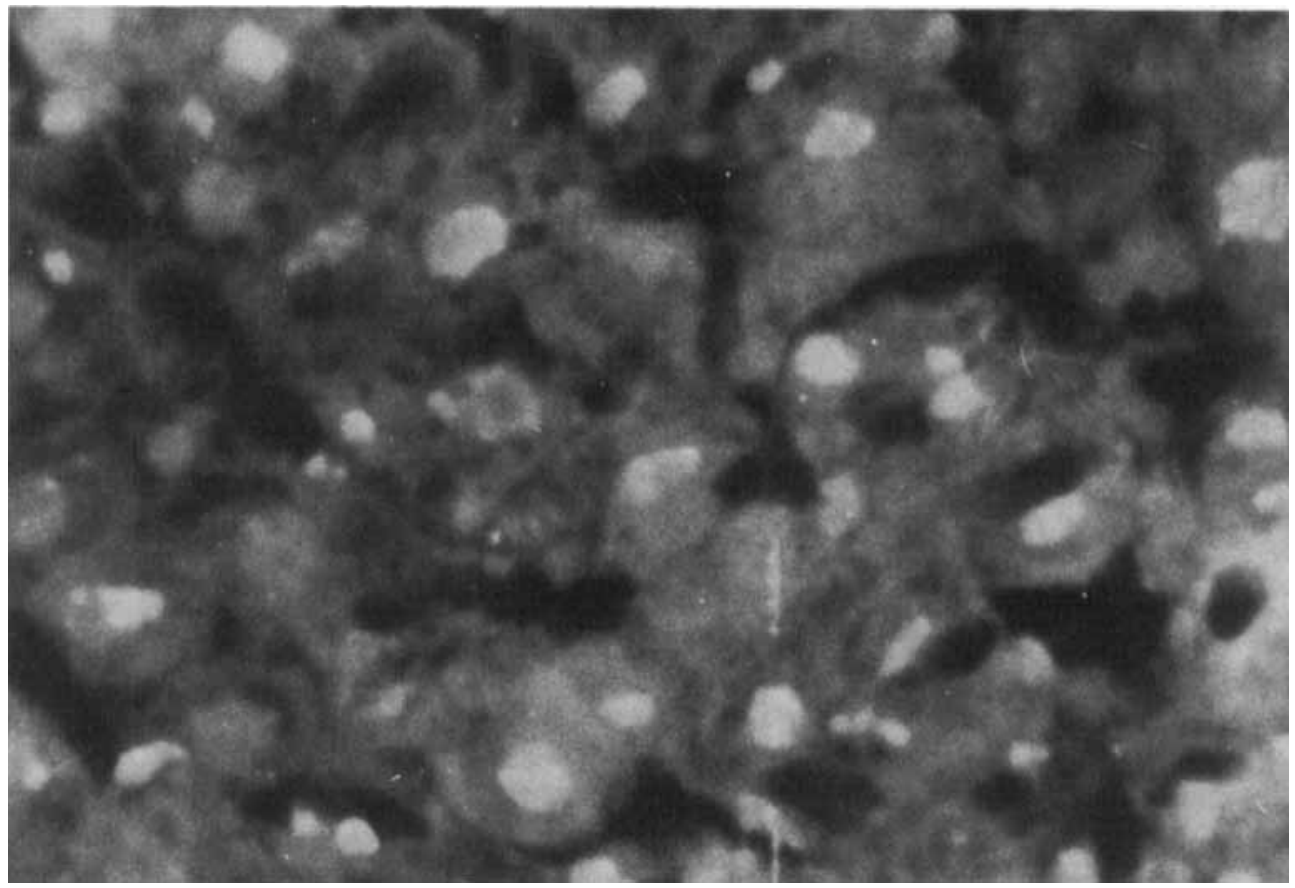

Figure $1 A$. B10 liver stained with JS-31 (bleed XXI). ANF reaction is positive.

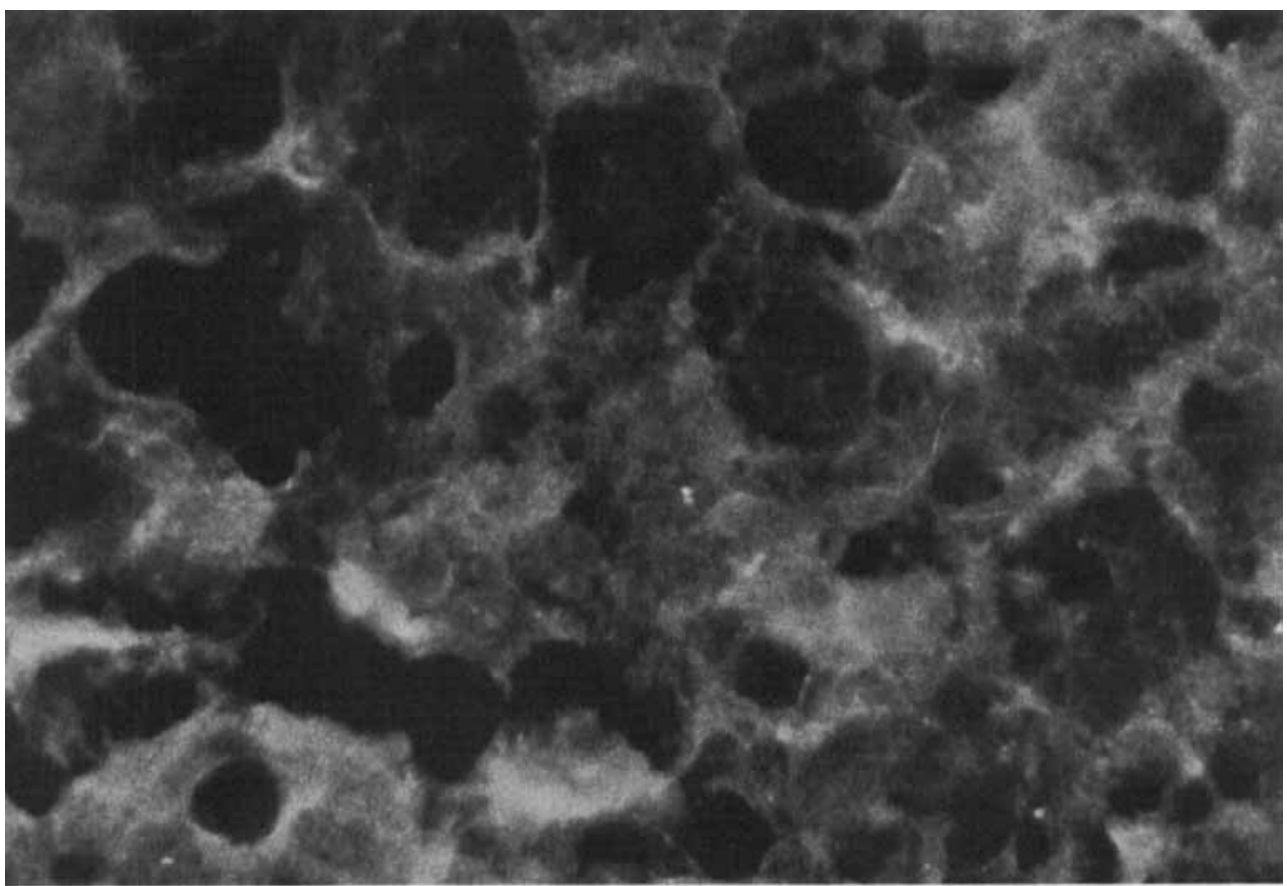

Figure $1 B$. B10.BR liver stained with B10.BR normal mouse serum. ANF reaction is negative. 
Titration of sera for antinuclear staining: $\mathrm{H}-2$ antisera that stained nuclei well at a dilution of $1 / 4$ were titrated employing the same staining protocol as used for the initial survey at $1 / 4$ dilution; except that the first layer was employed at dilutions of $1 / 10,1 / 20,1 / 40$, $1 / 80,1 / 160,1 / 320$, and $1 / 640$.

Microscopy: Some of these observations were conducted at the VA Medical Center in Ann Arbor, Michigan. The equipment at this location has been described by Saunders et al. (1979).

Most of the sera screened in Table 1 were observed at Howard University on a Leitz Dialux 29 microscope with epifluorescent lumination, a $25 \times$ objective, and a $12.5 \times$ eyepiece. The lamp was an HBO 50w manufactured by Osram. The filters were from Leitz system $H$, with a $2 \times$ KP 490 primary filter, a Tk 5 dichroic beam splitting mirror, and a K 515 secondary filter. Antisera that were positive for ANF, when tested with apparatus in Ann Arbor, were also positive for ANF when tested with apparatus available at Howard University.

\section{Results}

Table 1 presents the results of a survey of various anti-Thy, anti-Ly, and anti-H-2 sera for the presence of antinuclear factors that can be detected with fluorescent antimouse IgG. All of the antisera were scored for nuclear staining at a dilution of $1 / 4$. The titres of antisera with the most intense ANF staining are also listed.

The results show that anti-Thy 1.1 , but none of the anti-Ly sera, contains ANF. The anti-H-2 sera listed in Table 1 were obtained from a number of sources and were raised against a variety of different $\mathrm{H}-2$ specificites across various $\mathrm{H}-2$ subregional barriers; some but not all of these anti-H-2 sera contain ANF. We note that there is a particular tendency for sera directed against $\mathrm{H}-2.4$ or against $\mathrm{H}-2.31,34$ to contain ANF. We also note that individual normal mouse sera obtained from a variety of strains (B10, B10.D2, HTI, C3H, B10.Br, C3H.OL) of various ages (up to a year) seldom contain ANF above the $( \pm)$ level. Also, culture fluid obtained from a monoclonal cell line producing antibody against $\mathrm{H}-2^{\mathrm{k}}$ (Oi et al, 1978) does not show ANF.

The nuclear staining observed when the sera are reacted with air fixed tissue sections shows a pattern which may be described as streaked or fibrillar (Fernandez-Madrid \& Mattioli, 1976) or comet (Johnson et al. 1972). As noted by other investigators (Johnson et al. 1972) a ten minute fixation in acetone reduces the incidence of streaking. On the acetone fixed tissue sections the staining of the nucleus is either even (homogeneous) or else appears as an irregular, ragged stain at the nuclear periphery; this latter pattern has been described as shaggy, rim, or peripheral (Fernandez-Madrid \& Mattioli 1976). Photos of the nuclear staining pattern observed on acetone fixed sections with an anti-H-2 serum containing an intensely staining ANF and with a control serum are shown in Figures $1 \mathrm{a}$ and $1 \mathrm{~b}$, respectively.

Table 2 presents the results obtained when we compared the intensity of ANF staining (at a 1/4 dilution) by sera obtained at different times during the course of various immunizations conducted in our laboratory. We note that ANF is not present in early bleeds, and that ANF staining becomes more intense through the course of the immunization. For reasons that are not apparent, the final bleeds from many of these immunizations contain ANF that stains less intensely than the ANF in other bleeds obtained near the end of the immunization schedule. 
Table 2

ANF Appearance During Time Course of Various Immunizations

\begin{tabular}{|c|c|c|c|c|c|}
\hline $\begin{array}{l}\text { Bleed } \\
\text { number }\end{array}$ & JS-9 & JS-31(1) & $\begin{array}{l}\text { Antiserum } \\
\text { JS-31(2) }\end{array}$ & JS-31 & JS-bak \\
\hline I & $\mathrm{ND}^{*}$ & $($ pool I-III) & - & ND & (pool I-III) \\
\hline II & ND & & - & ND & \\
\hline III & ND & & - & ND & \\
\hline IV & ND & ND & - & ND & - \\
\hline $\mathrm{V}$ & ND & + & - & ND & ND \\
\hline VI & ND & ND & \pm & ND & + \\
\hline VII & ND & ND & \pm & ND & $\stackrel{ \pm}{ \pm}$ \\
\hline VIII & - & ND & + & ND & \\
\hline IX & ND & $\begin{array}{c}++ \\
(\text { pool IX-X) }\end{array}$ & + & $\stackrel{ \pm}{ \pm}($ pool IX-X) & \\
\hline $\mathrm{X}$ & - & & ++ & & \\
\hline$X I$ & ND & $\begin{array}{c}+++ \\
\text { (pool XI-XII) }\end{array}$ & +++ & ND & \\
\hline XII & - & & $\stackrel{+}{\stackrel{+}{\text { (final bleed) }}}$ & - & \\
\hline XIII & ND & $++t$ & & ND & \\
\hline XIV & ND & ND & & ND & \\
\hline$X V$ & - & ++++ & & - & \\
\hline XVI & ND & ++++ & & - & \\
\hline XVII & ND & ++++ & & \pm & \\
\hline XVIII & ND & +++ & & + & \\
\hline XIX & $\stackrel{-}{\text { (final bleed) }}$ & ND & & ND & \\
\hline $\mathrm{XX}$ & & ++++ & & + & \\
\hline $\mathrm{XXI}$ & & ++++ & & $\stackrel{+}{\text { (final bleed) }}$ & \\
\hline XXII & & $\begin{array}{c}+++ \\
\text { (final bleed) }\end{array}$ & & & \\
\hline
\end{tabular}

*Not determined

\section{Discussion}

Of the antisera listed in Table 1, we consider only those scored with a nuclear stain of $(+)$ or greater as having definite ANF. We note that anti-Thy 1.1 and some, but not all, $\mathrm{H}-2$ alloantisera contain ANF of a moderate titre. This ANF, we believe, has been induced as a result of alloimmunization, since individual NMS that we have obtained from mice of various ages from a number of strains seldom show ANF above the level of $( \pm)$.
Our data may underestimate the actual incidence of ANF in various anti-H-2 sera, since only the late bleedings of antisera produced in our laboratory had moderately titred ANF while early bleedings of these antisera did not show any ANF activity. Since we received pools of early and late bleedings from other laboratories, we may have seen only a marginal ANF staining in some pools due to dilution of the ANF into the volume of the earlier bleeds. Another factor that may obscure the detection of ANF could be that some of the 
anti-H-2 sera (e.g. D-33) have a strong generalized background stain noted by Saunders et al. (1979); strong background stain could obscure weak nuclear stains.

Despite the above factors which may prevent detection of ANF, there are some immunizations against $\mathrm{H}-2$ which do not give rise to ANF. For example, individual late bleedings from JS-9 prepared in our laboratory showed no nuclear staining (see Table 2).

From our data we cannot define any specific $\mathrm{H}-2$ subregional barrier between donor and host that might be required for the induction of ANF in anti-H-2 sera. For example, the strong nuclear staining observed with the various anti-H-2.31,34 sera and with Ia.2 might suggest that an A,B subregional barrier is crucial; on the other hand there are antisera, such as those against $\mathrm{H}-2.4$, which are raised across an $\mathrm{H}-2 \mathrm{D}$ barrier and which also contain ANF.

We do not believe that antinuclear staining by anti-H-2 sera is due to anti-H-2 antibodies. Several ANF positive sera were reacted with tissue sections from a number of different mouse strains, some positive and some negative for the $\mathrm{H}-2$ specificities contained in the antisera. Antinuclear staining was detected on all tissue sections whether or not there was H-2 staining. Since this nuclear staining also appears on tissue sections prepared from recipient type mice, the ANF is apparently of an autoimmune nature.

With regards to the anit-Thy 1.1 serum, we believe the nuclear staining observed with this antiserum is not related to staining of Thy 1.1 antigen. The liver sections with which this antiserum was reacted were from strain B10, which is negative for Thy 1.1 antigen; also, the Thy antigens should not be present on liver tissue (J. Klein 1975).

Antinuclear factors or antibodies (ANA) have been detected in experimental animals under a variety of conditions. We shall now discuss mechanisms that might be operative in the appearance of ANF during alloimmunization.

1) Spontaneous appearance of $A \dot{N} F$ : The appearance of ANF could be spontaneous and not actually related to alloimmunization. For example, ANF incidence increases with age in many but not all inbred strains of mice (Barnes \& Tuffrey 1967, Friou \& Teague 1964, Norins \& Holmes 1967, Siegel et al. 1972, Yunis et al. 1972). For most of the antisera in Table 1 the age of the recipient is unknown, and conceivable ANF might appear in some antisera simply by virtue of the fact that the recipient mice were aging and would have produced ANF whether or not they had been alloimmunized.

2) ANF induced infection: ANF has also been found in experimental animals following infection with Gram-negative bacteria (Christian et al. 1965, Grabar et al. 1968), virus (Cannat \& Varet 1972, Dixon et al. 1974, Allison 1977), or parasites (Lambert \& Houba 1974). Conceivably infection of the recipients during the course of the immunization might account for the appearance of ANF. However, infection by an exogenous agent cannot account for our results, since we have never noted significant ANF staining with any of the normal mouse sera obtained from individual mice housed in the same animal quarters during the time at which ANF positive anti-H-2 sera were raised in our laboratory.

3) Release of latent virus: The induction of ANF by $\mathrm{H}-2$ alloimmunization could also be a process that is secondary to the release of latent virus. It is known, for example, that activation of murine leukemia virus can result from chronic immunization with $\mathrm{H}-2$ antigens via the graft-versus-host (GVH) or hostversus-graft (HVG) reactions (Hirsch et al. 1973). Once activated such virus might initiate processes leading to autoimmunity.

4) ANF induced by tissue destructions: It is known that tissue destruction can lead to the 
appearance of anti-DNA antibodies, depending upon the genetic constitution of the host (Fournie et al. 1976). In the case of alloimmunization it could be that, as the grafted innoculum cells are destroyed by the immune response of the host, there is a release of DNA and other nuclear material that then evokes an immune response.

5) Transfer of autoimmune state with old donor cells: Teague \& Friou (1969) have demonstrated that a transfer of live or disrupted spleen cells from old donors to syngeneic young recipients can lead to an accelerated appearance (during aging) of ANA in the young recipients. The nature of what is transferred with old cells to induce autoimmunity is unclear from their experiments. Among possible inducing agents are an infectious agent, such as virus, or a macromolecular factor controlling immune cell function. If the inducing agent can also operate across allogeneic barriers, then the appearance of ANF in some alloantisera might result if the donor cells were derived from old mice. We cannot ascertain whether such a mechanism might lead to ANF induction in any of the antisera that we have examined since none of the investigators producing the antisera have monitored donor cell age. If donor cell age is the sole factor responsible for ANF induction, it is difficult to explain why there is such a tendency for ANF to be associated with antisera from several different immunizations against certain sets of $\mathrm{H}-2$ specifities (e.g. the antisera against $\mathrm{H}-2.4$ or $\mathrm{H}-2.31,34)$ but not against other $\mathrm{H}-2$ specificities (e.g. $\mathrm{H}-2.9$ ).

6) ANF induction by the allogeneic effect: The induction of ANF in anti-H-2 sera may be due to the special nature of the $\mathrm{H}-2$ alloantigenic stimulus per se. It has been predicted that $T$-cell reactions against histoincompatible cells should provide for allogeneic stimulation of antiself B-cells (Allison et al. 1971). This prediction has been confirmed in the case of GVH disease (Fialkow et al.
1973). In this case the grafted parental strain cells react against $F_{1}$ histoincompatible antigens and apparently release allogeneic factors which allow host B-cells to produce autoantibodies, including ANA. Though the grafted parental cells and $F_{1}$ host in this experiment differed at both major and minor histocompatibility loci, it has been argued (Gleichmann et al. 1976) that it is most likely the difference at the major histocompatibility complex (MHC) which is critical for the allogeneic induction of autoimmunity in the $F_{1}$ recipient. The appearance of autoimmune reactions associated with HVG responses has been less well studied than with GVH reactions; however, such a mechanism could conceivably be operating to induce ANF in some anti-H-2 sera.

The presence of ANF in sera raised against non-MHC alloantigens such as Thy 1.1 , might also result from the allogeneic effect if the immune responses to these antigens are $\mathrm{MHC}$ restricted. It has been argued (Gleichmann et al. 1976) that MHC restricted immune responses could lead to antiself B-cell stimulation via the allogeneic effect.

The present experiments do not allow us to determine which one or more of the above mechanisms may induce ANF in alloantisera. It is unlikely that any of these mechanisms except 1) or 2) would explain the presence of ANF in anti-Slp, which is raised by immunization with a partially purified protein; we note, however, that immunization with a purified protein such as BSA can induce ANF (Teague et al. 1968). We cannot correlate the presence of ANF with the immunization of any particular strain or with immunization across any $\mathrm{H}-2$ subregional barriers. Since our data may underestimate ANF incidence, any such correlations would be unwarranted. 


\section{Acknowledgments}

We are grateful for a gift of Gelvatol 20-30 from the Monsanto Chemical Company. We wish to thank Dr. Jan Klein, Dr. Chella David, and Dr. Michael Edidin for gifts of antisera. The technical assistance of Cheryl Elston and Dierdre Smith is appreciated. We thank Dr. Curla Walters and Dr. Calbert Laing for the loan of microscope facilities. We are thankful for the many helpful comments from Dr. Georgia Dunston during the preparation of the manuscript.

This research was supported by NCI grant CA 18638 to Dr. Jane Schultz and the Medical Research Service of the Veterans Administration. Additional funding was provided by a Howard Basic Research Support Grant to Dr. David Saunders from the Howard Graduate School of Arts \& Sciences.

Manuscripts were skillfully typed by Judy Saunders.

\section{References}

Allison, A. C. (1977) Autoimmune diseases: concepts of pathogenesis and control. Autoimmunity: genetic, immunologic, virologic, and clinical aspects. ed. Talal, N., pp. 91-139. Academic Press, New York.

Allison, A. C., Denman, A. M. \& Barnes, R. D. (1971) Cooperating and controlling functions of thymus-derived lymphocytes in relation to autoimmunity. Lancet 2, 135-140.

Barnes, R. D. \& Tuffrey, M. (1967) Serum antinuclear factor and the influence of environment. Nature (London) 214, 1136-1138.

Cannet, A. \& Varet, B. (1972) Induction of antinuclear antibodies in $\left(\mathrm{C} \times \mathrm{B}_{6}\right) \mathrm{F}_{1}$ mice innoculated with Graffi and Rauscher leukemogenic viruses. Proc. Soc. Exp. Biol. Med. 141, 1077-1080.

Christian, C. L., Desimone, A. R. \& Azhuzzo, J. L. (1965) Anti-DNA antibodies in hyperimmunized rabbits. J. Exp. Med. 121, 309-321.

Dixon, F., Croker, B., Delvillano, B., Jensen, F. \& Lerner, R. (1974) Oncornavirus infection and 'auto' immune complex disease of mice. Progr.
Immunol. II, Vol 5, eds. Brent, L. \& Holborow, J., pp. 49-55. North Holland Publishing Co., Amsterdam.

Fernandez-Madrid, F. \& Mattioli, M. (1976) Antinuclear antibodies (ANA): immunological and clinical significance. Sem. Arth. Rheum. 6, 83-124.

Fialkow, P. J., Gilchrist, C. \& Allison, A. C. (1973) Autoimmunity in chronic graft-versus-host disease. Clin. Exp. Immunol. 13, 479-486.

Fournie, G. J., Izui, S., Lambert, P. H. \& Conte, J. J. (1976) Genesis and pathogenecity of antiDNA antibodies. Adv. Nephrol. 6, 47-61.

Friou, G. J. \& Teague, P. O. (1964) Spontaneous autoimmunity in mice: antibodies to nucleoprotein in strain A/J. Science 143, 1333-1334.

Gervais, A. G. (1968) Detection of mouse histocompatibility antigens by immunoflourescence. Transplantation 6, 261-276.

Gleichmann, E., Gleichmann, H. \& Wilke, W. (1976) Autoimmunization and lymphomagenesis in parent- $F_{1}$ combinations differing at the major histocompatibility complex: model for spontaneous disease caused by altered self-antigens. Transpl. Rev. 31, 156-224.

Grabar, P., Avrameas, S., Taudou, B. \& Solomon, J. C. (1968) Formation and isolation of antibodies specific for nucleotides. Nucleic Acids in Immunology, eds. Plescia, O. J. \& Braun, W. pp. 79-87. Springer-Verlag, New York.

Hirsch, M. S., Ellis, D. A., Black, P. H., Monaco, A. P. \& Wood, M. L. (1973) Leukemia virus activation during homograft rejection. Science 180, 500-502.

Ivanyi, P., Melife, C. J. M., Greeve, P. de \& van Mourik, P. (1979) Individual mice recognize the complex nature of $\mathrm{H}-2$ antigens; unexpected reactions (anti- $\mathrm{K}^{\mathrm{k}}$ ) in anti-BALB/c-H-2 ${ }^{d}$ sera produced in the BALB/c-H-2 ${ }^{\text {db }}$ mutant. Transplant. Proc. 11, 642-646.

Johnson, G. D., Smith, M. E. \& Holborow, E. J. (1972) The comet pattern of nuclear immunofluorescence. Clin. Exp. Immunol. 10, 463-468.

Klein, J. (1975) Biology of the mouse histocompatibility-2 complex, p. 159. Springer-Verlag, New York.

Klein, J., Flaherty, L., Van de Berg, J. L. \& Shreffler, D.C. (1978) H-2 haplotypes, genes, regions, and antigens: first listing. Immunogenetics 6, 489-512.

Klein, P. A. (1975) Anomolous reactions of mouse alloantisera with cultured tumor cells I. Demonstration of widespread occurrence using reference type sera. J. Immunol. 115, 1254-1260. 
Lambert, P. H. \& Houba, V. (1974) Immune complexes in parasitic diseases. Prog. Immunol. II, vol. 5, eds. Brent, L. \& Holborow, J., pp. 57-67. North Holland Publishing Co., Amsterdam.

Langdon, W. Y., Shellam, G. R., Morgan, G. M. \& McKenzie, I. F. C. (1980) High titres of antibody to murine leukemia virus in lymphocyte (Ly) antisera. Immunogenetics 10, 141-150.

Norins, L. C. \& Holmes, M. C. (1964) Antinuclear factor in mice. J. Immunol. 93, 148-154.

Nowinski, R. C. \& Klein, P. A. (1975) Anomalous reactions of mouse alloantisera with cultured tumor cells II. Cytotoxicity is caused by antibodies to leukemia viruses. J. Immunol. 115, 1261-1268.

Oi, V. T., Jones, P. P., Goding, J. W., Herzenberg, L. A. \& Herzenberg, L. A. (1978) Properties of monoclonal antibodies to mouse Ig allotypes, H-2, and Ia antigens. Current Top. Microbiol. Immunol. 81, 115-129.

Saunders, D. A., Beals, T. F. \& Schultz, J. S. (1979) Qualitative and quantitative evaluation of indirect immunofluorescent $\mathrm{H}-2$ stain on tissue sections. Tissue Antigens 14, 73-85.
Siegel, B. V., Brown, M. \& Morton, J. I. (1972) Detection of antinuclear antibodies in NZB and other mouse strains. Immunol. 22, 457-463.

Teague, P. O. \& Friou, G. J. (1969) Antinuclear antibodies in mice II. Transmission with spleen cells; inhibition or prevention with thymus or spleen cells. Immunol. 17, 665-675.

Teague, P. O., Friou, G. J. \& Myers, L. L. (1968) Antinuclear antibodies in mice I. Influence of age and possible genetic factor in spontaneous and induced responses. J. Immunol. 101, 791-798.

Yunis, E. J., Fernandes, G., Teague, P. O., Stutman, O. \& Good, R. A. (1972) The thymus, autoimmunity, and involution of the lymphoid system. Tolerance Autoimmunity and Aging, eds. Sigel, M. M. \& Good, R. A., pp. 62-119. C. C. Thomas, Springfield, Illinois.

\section{Address:}

David A. Saunders, Ph.D.

Department of Zoology

Howard University

Washington, D.C. 20059

U.S.A. 